\title{
Dose-response effects of exercise on insulin among colon cancer survivors
}

\author{
Justin C Brown', Michael R Rickels², Andrea B Troxel33, Babette S Zemel2,4, Nevena Damjanov², Bonnie Ky², \\ Andrew D Rhim 5 , Anil K Rustgi², Kerry S Courneya ${ }^{6}$ and Kathryn H Schmitz'
}

'Dana-Farber Cancer Institute, Boston, Massachusetts, USA

2University of Pennsylvania, Philadelphia, Pennsylvania, USA

${ }^{3}$ New York University, New York, New York, USA

${ }^{4}$ Childrens Hospital of Philadelphia, Philadelphia, Pennsylvania, USA

5 MD Anderson Cancer Center, Houston, Texas, USA

${ }^{U}$ University of Alberta, Edmonton, Alberta, Canada

7Penn State College of Medicine, Hershey, Pennsylvania, USA

Correspondence should be addressed to J C Brown: justinc_brown@dfci.harvard.edu

\begin{abstract}
Physical activity is associated with a lower risk of disease recurrence among colon cancer survivors. The pathways through which physical activity may alter disease outcomes are unknown, but may include changes in metabolic growth factors, such as insulin. Between January 2015 and August 2015, 39 stage I-III colon cancer survivors were randomized to one of the three groups: usual care control, $150 \mathrm{~min} /$ week of aerobic exercise (low-dose) and $300 \mathrm{~min} /$ week of aerobic exercise (high-dose) for six months. The pre-specified key metabolic growth factor outcome was fasting insulin. Insulin resistance was quantified using the homeostatic model assessment. Mean age was $56.5 \pm 10.0$ years, $51 \%$ had stage III disease, $72 \%$ were treated with chemotherapy and the mean time since finishing treatment was $10.9 \pm 6.1$ months. Over six months, the low-dose group completed $141.5 \pm 9.9 \mathrm{~min} /$ week of aerobic exercise, and the high-dose group completed $247.2 \pm 10.7 \mathrm{~min} /$ week of aerobic exercise. Fasting insulin concentrations decreased $7.4 \pm 9.4 \mathrm{pmol} / \mathrm{L}$ in the control group, $28.0 \pm 8.3 \mathrm{pmol} / \mathrm{L}$ in the low-dose group and $20.7 \pm 9.3 \mathrm{pmol} / \mathrm{L}$ in the high-dose group (nonlinear $P_{\text {trend }}=0.042$ ). Insulin resistance decreased $0.11 \pm 0.20$ in the control group, $0.63 \pm 0.17$ in the low-dose group and $0.43 \pm 0.19$ in the high-dose group (nonlinear $P_{\text {trend }}=0.012$ ). Aerobic exercise reduces insulin concentrations and insulin resistance among patients with stage I-III colon cancer. Prescribing $150 \mathrm{~min} /$ week of aerobic exercise may be sufficient for reducing insulin concentrations and insulin resistance, which may partially mediate the relationship between physical activity and colon cancer prognosis.
\end{abstract}
Key Words
- body composition
- metabolism
- physical activity
- prevention
- randomized trial
- recurrence

\section{Introduction}

Each year, more than 103,000 people are diagnosed with colon cancer in the United States (Siegel et al. 2016). Threequarters of patients will be diagnosed with disease that is localized to the colon (stage I-II) or spread to regional lymph nodes (stage III). Despite surgical resection, either alone or in combination with chemotherapy, up to one-half of the patients with stage I-III colon cancer will experience disease recurrence (Siegel et al. 2014). 
Consequently, there exists a need to identify additional therapies that reduce the risk of recurrent disease in this population.

The prescription of physical activity or exercise is a potential therapy that has been reported in observational studies to be associated with a lower risk of recurrence and death among colon cancer survivors (Je et al. 2013). The relationship between physical activity and disease outcomes is independent of known prognostic factors, and occurs in a dose-response fashion, such that higher volumes of physical activity or exercise, up to $300 \mathrm{~min}$ per week (min/week), are associated with more favorable disease outcomes (Schmid \& Leitzmann 2014).

The biologic or biobehavioral pathways through which exercise may favorably alter colon cancer outcomes have not been elucidated, but may include exerciseinduced alterations in metabolic growth factors, such as insulin, C-peptide, insulin-like growth factor-1 (IGF-1) and insulin-like growth factor-binding protein-3 (IGFBP3). Colon cancer cells have insulin/IGF-1 receptors on their surface (Belfiore \& Malaguarnera 2011), and insulin/IGF-1 promote colon cancer cell proliferation and inhibit apoptosis (Koenuma et al. 1989). In vitro studies demonstrate that states of hyperinsulinemia increase colon cancer cell resistance to 5-fluorouracil (Chen et al. 2011b) and oxaliplatin chemotherapy (Chen et al. 2011a, Volkova et al. 2014). Preclinical models demonstrate that exposure to insulin promotes colonic tumor multiplicity (Tran et al. 1996), and IGF-1 promotes a prometastatic hepatic microenvironment for colon cancer cells (Fernandez et al. 2016). In the general population, hyperinsulinemia is associated with an increased risk of cancer-specific mortality (Wargny et al. 2017). Among men and women with stage I-III colon cancer, elevated concentrations of C-peptide and lower concentrations of IGFBP-3 are associated with a higher risk of mortality (Haydon et al. 2006, Wolpin et al. 2009). Genetic variants within insulin-related genes are associated with colon cancer risk, recurrence and survival (Simons et al. 2015, $\mathrm{Fu}$ et al. 2016). Together, this evidence supports the hypothesis that insulin/IGF-1 may be important mediators of the relationship between exercise and disease outcomes among colon cancer survivors.

Colon cancer survivors have fasting insulin concentrations that are 58\% higher than healthy persons without a history of colon cancer (Jiang et al. 2014). A study of 17 colon cancer survivors demonstrated that a three-month prescription of exercise reduced insulin and IGFBP-3 concentrations (Lee et al. 2013). However, no studies have examined the dose-response effects of exercise on these metabolic growth factors among colon cancer survivors.

These observations provided the scientific rationale for the COURAGE trial, a randomized controlled trial investigating the safety, feasibility and biological efficacy of 150 and $300 \mathrm{~min} /$ week of aerobic exercise vs usual care control over six months among men and women recently treated for stage I-III colon cancer (Brown et al. 2016). We have previously reported that exercise was safe, feasible and led to reductions in serum intercellular adhesion molecule-1 (Brown et al. 2017a) and visceral adipose tissue (Brown et al. 2017b). Here, we report metabolic growth factor outcomes. Fasting insulin was pre-specified as the key growth factor of interest. As an exploratory aim of this report, we characterize the relationship between changes in visceral adipose tissue with changes in fasting insulin. Our hypotheses were that: (1) exercise would reduce fasting insulin concentrations in a dose-response fashion; (2) reductions in visceral adipose tissue would correlate with reductions in fasting insulin.

\section{Materials and methods}

\section{Participants}

Study methods of the COURAGE trial were published (Brown et al. 2016). Participants were eligible if they: (1) were diagnosed with histologically proven stage I-III colon cancer; (2) completed surgical resection and postoperative chemotherapy within 36 months of entering the study; (3) self-reported participation in $\leq 150 \mathrm{~min} /$ week of moderate or vigorous intensity physical activity using the Paffenbarger Physical Activity Questionnaire (Paffenbarger et al. 1978); (4) were of age $\geq 18$ years; (5) provided written physician approval; (6) had no additional surgery planned within the six-month intervention period (including colostomy reversal) and (7) had the ability to walk unassisted for six minutes. Participants were ineligible if they: (1) had a history of another primary cancer (other than nonmelanoma skin cancer); (2) had evidence of metastatic cancer; (3) were pregnant or breast feeding; (4) were unable to provide a baseline blood sample; (5) had a myocardial infarction or coronary revascularization procedure within the past three months; (6) had uncontrolled hypertension, defined as a systolic blood pressure $\geq 180 \mathrm{mmHg}$ or diastolic blood pressure $\geq 100 \mathrm{mmHg}$; (7) had high-risk or uncontrolled heart arrhythmias (not including atrial fibrillation); (8) had clinically significant heart valve disease; (9) had decompensated heart failure; (10) had a known aortic 
aneurysm or (11) had any other condition which, in the opinion of the investigator, may impede testing of the study hypothesis or make it unsafe to engage in the exercise program.

Participants were stratified by the cancer stage (AJCC 7th Edition: I vs II vs III) and randomized to one of the three groups: low-dose aerobic exercise ( $150 \mathrm{~min} /$ week), high-dose aerobic exercise (300 min/week) or usual care control. This study was approved by the University of Pennsylvania Institutional Review Board and registered on clinicaltrials.gov as NCT02250053. All participants provided written informed consent and written approval from their physician prior to participation in any studyrelated activities.

\section{Intervention}

Detailed methods of the exercise intervention are published (Brown et al. 2016). Participants randomized to the low-dose or high-dose exercise groups were provided with an in-home treadmill (LifeSpan Fitness, TR1200i, Salt Lake City, UT, USA) and heart rate monitor (Polar Electro, RS400, Kempele, Finland). Exercise intensity was prescribed at $50-70 \%$ of the age-predicted maximum heart rate (equivalent to 3-6 METs; (Ainsworth et al. 2000)). The low-dose and high-dose groups progressed toward the goal of 150 or $300 \mathrm{~min} /$ week of exercise, respectively. Participants met with a certified clinical exercise physiologist to introduce the exercise prescription and familiarize the participant with the use of the treadmill, completion of exercise logs, use of a heart rate monitor, appropriate warm-up and cool-down, stretches and proper footwear for aerobic exercise. The exercise physiologist provided ongoing behavioral and clinical support and monitored exercise adherence to the study protocol throughout the duration of the study.

Participants randomized to the usual care control group were asked to maintain their pre-study levels of physical activity or follow the recommendations provided by their physician. After completing six-month measures, control group participants were provided with an in-home treadmill and individualized exercise program, like that prescribed to the two exercise groups. Upon completion of study-related activities, all participants could keep their study-provided treadmills.

\section{Measurements}

Baseline and follow-up measurements were obtained by trained staff members who were blinded to treatment assignment. Demographic characteristics including age, sex and race were self-reported. Daily caloric intake and the proportion of calories from carbohydrate sources were quantified using three-day diet records that were analyzed using the Nutrition Data System for Research software (v.2014) by a registered dietitian who was blinded to the study group. Moderate-to-vigorous intensity physical activity was quantified using an accelerometer (ActiGraph GT3X+; (Troiano et al. 2008)). Clinical information including cancer stage and treatment with chemotherapy were obtained from the cancer registry, pathology reports and physician records. Body mass index (BMI; $\mathrm{kg} / \mathrm{m}^{2}$ ) was calculated using standard anthropometric measures (weight $(\mathrm{kg})$ and height $(\mathrm{m})$ ), and dual-energy X-ray absorptiometry was used to quantify visceral adipose tissue (Brown et al. 2017b). Comorbid health conditions were self-reported.

\section{Metabolic growth factor outcomes}

All study participants underwent a fasting blood draw at baseline and follow-up. EDTA-preserved plasma was stored at $-80^{\circ} \mathrm{C}$. Insulin and $\mathrm{C}$-peptide concentrations were quantified using a radioimmunoassay (EMD Millipore). IGF-1, IGFBP-3 and fructosamine concentrations were quantified using an enzyme-linked immunosorbent assay (DSL, Webster, TX, USA). Glucose concentrations were quantified spectrophotometrically (Roche). Baseline and follow-up plasma samples were assayed simultaneously and in duplicate at the end of the study. Coefficients of variation for all samples were $\leq 10 \%$. The homeostatic model assessment (HOMA) was used to quantify insulin resistance (Levy et al. 1998).

\section{Statistical analysis}

Descriptive statistics presented for baseline variables include counts and proportions for categorical variables and medians with interquartile (25-75\%) ranges for continuous variables. Categorical baseline characteristics were compared among the three groups using Fisher's exact test, and continuous baseline characteristics were compared among the three study groups using the Kruskal-Wallis test. This trial was statistically powered to detect changes in the co-primary study endpoints soluble intercellular adhesion molecule-1 and soluble vascular adhesion molecule-1 (Brown et al. 2016, 2017a). However, the study had adequate statistical power to examine changes in fasting insulin concentrations. Based on prior research (Houmard et al. 2004), over six 
months, we estimated a mean change in fasting insulin concentrations of $+6.6 \mathrm{pmol} / \mathrm{L}$ in the control group, $-3.3 \mathrm{pmol} / \mathrm{L}$ in the low-dose group and $-5.9 \mathrm{pmol} / \mathrm{L}$ in the high-dose group with a pooled standard deviation of $\pm 4.6 \mathrm{pmol} / \mathrm{L}$. Against the hypothesis of a dose-response relationship, 39 participants provided $80 \%$ power with a type I error rate of $5 \%(\alpha=0.05)$. All inferential analyses were conducted on an intention-to-treat basis. Dependent variables were $\log$ transformed in the inferential analysis to improve distributional normality and back transformed to facilitate interpretation. Changes were evaluated from baseline to follow-up in the three groups using repeated-measures mixed-effects regression models. This statistical approach includes all available data and accounts for the correlation between repeated measures. The baseline values of the dependent variable and cancer stage (randomization stratification factor) were included as covariates in the regression models (Fitzmaurice et al. 2012). Group-by-time interaction terms were included as fixed effects in the regression model. Model fit was assessed using graphical techniques. Results from the repeated-measures mixed-effects regression models are presented as least-squares means \pm standard error or $95 \%$ confidence intervals. To evaluate the presence of a dose-response relationship across randomized groups, a test of trend was conducted by examining linear and nonlinear (quadratic) contrasts. Linear regression models were used to characterize changes in visceral adipose tissue with changes in growth factor concentrations from baseline to six months (Schousboe et al. 2017).

\section{Results}

Between January 2015 and August 2015, 39 colon cancer survivors were recruited and randomized with data collection ending in February 2016. Baseline characteristics of study participants have been described (Brown et al. $2017 a$ ), and are briefly presented in Table 1 . Age ranged from 35 to 81 years. BMI ranged from 20 to $43 \mathrm{~kg} / \mathrm{m}^{2} ; 31 \%$ of the participants were overweight (BMI $25.0-29.9 \mathrm{~kg} / \mathrm{m}^{2}$ ) and $51 \%$ were obese $\left(\mathrm{BMI} \geq 30 \mathrm{~kg} / \mathrm{m}^{2}\right)$. Visceral adipose tissue ranged from 34.2 to $257.9 \mathrm{~cm}^{2}$. Time since finishing cancer-directed treatment ranged from 1 to 21 months. Five participants had type 2 diabetes mellitus at baseline, all were diagnosed $\geq 3$ years prior to study enrollment and all were using metformin (one as monotherapy, four as combination therapy with a sulfonylurea or dipeptidyl peptidase-4 inhibitor).

Table 1 Baseline characteristics of the participants.

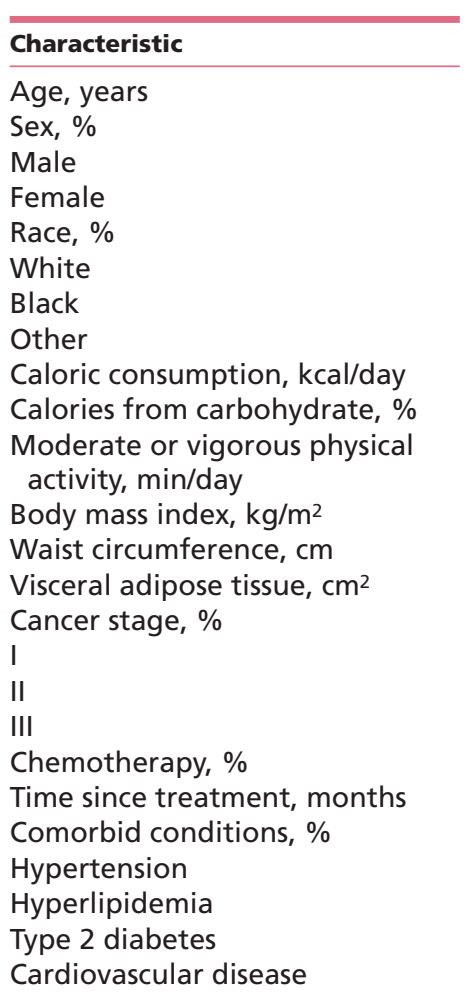

\begin{tabular}{|c|c|}
\hline Total $(n=39)$ & Control $(n=13)$ \\
\hline $56.5(49.1-63.3)$ & 56.5 (51.0-60.9) \\
\hline $15(38 \%)$ & $4(31 \%)$ \\
\hline $24(62 \%)$ & $9(69 \%)$ \\
\hline $31(80 \%)$ & $8(62 \%)$ \\
\hline $6(15 \%)$ & $3(23 \%)$ \\
\hline $2(5 \%)$ & $2(15 \%)$ \\
\hline 1735 (1270-1962) & $1800(1233-2110)$ \\
\hline $46.8(39.7-51.3)$ & $43.5(36.9-49.4)$ \\
\hline $15.7 \pm 8.7$ & $12.2 \pm 8.1$ \\
\hline $30.3(25.3-35.3)$ & $29.0(25.0-33.5)$ \\
\hline $102(91-110)$ & $94(90-107)$ \\
\hline $130.8(82.2-168.8)$ & $116.7(61.4-150.3)$ \\
\hline $5(13 \%)$ & $1(8 \%)$ \\
\hline $14(36 \%)$ & $5(38 \%)$ \\
\hline $20(51 \%)$ & $7(54 \%)$ \\
\hline $28(72 \%)$ & $10(77 \%)$ \\
\hline $10(5-16)$ & $12(8-16)$ \\
\hline $13(33 \%)$ & $4(31 \%)$ \\
\hline $6(15 \%)$ & $1(8 \%)$ \\
\hline $5(13 \%)$ & $1(8 \%)$ \\
\hline $4(10 \%)$ & $2(15 \%)$ \\
\hline
\end{tabular}

\begin{tabular}{c} 
Low-dose $(n=14)$ \\
\hline $59.1(54.3-66.4)$ \\
$7(50 \%)$ \\
$7(50 \%)$ \\
$12(86 \%)$ \\
$2(14 \%)$ \\
$0(0 \%)$ \\
$1776(1483-2111)$ \\
$48.7(46.0-54.8)$ \\
$18.8 \pm 9.6$ \\
$30.4(27.1-32.1)$ \\
$99(91-107)$ \\
$133.0(82.2-162.1)$ \\
$2(14 \%)$ \\
$5(36 \%)$ \\
$7(50 \%)$ \\
$10(71 \%)$ \\
$7.5(4-13)$ \\
$6(43 \%)$ \\
$2(14 \%)$ \\
$1(7 \%)$ \\
$1(7 \%)$ \\
\end{tabular}

\begin{tabular}{|c|c|}
\hline High-dose $(n=12)$ & $\boldsymbol{P}$ \\
\hline $54.6(45.0-62.0)$ & 0.493 \\
\hline $4(33 \%)$ & 0.601 \\
\hline $8(67 \%)$ & \\
\hline $11(92 \%)$ & 0.332 \\
\hline $1(8 \%)$ & \\
\hline $0(0 \%)$ & \\
\hline 1632 (1196-1739) & 0.725 \\
\hline $37.7(45.1-51.3)$ & 0.261 \\
\hline $15.7 \pm 7.3$ & 0.174 \\
\hline $33.6(25.6-37.7)$ & 0.408 \\
\hline $109(110-114)$ & 0.154 \\
\hline $138.8(117.4-206.6)$ & 0.227 \\
\hline $2(17 \%)$ & 0.999 \\
\hline $4(33 \%)$ & \\
\hline $6(50 \%)$ & \\
\hline $8(67 \%)$ & 0.906 \\
\hline $10(6-17)$ & 0.417 \\
\hline $3(25 \%)$ & 0.695 \\
\hline $3(25 \%)$ & 0.480 \\
\hline $3(25 \%)$ & 0.409 \\
\hline $1(8 \%)$ & 0.827 \\
\hline
\end{tabular}

$P$ values are from the overall test of group differences. Data are median (interquartile range), mean \pm S.D. or counts with percentages. 
Exercise prescription program variables have been described in detail (Brown et al. 2017a). Over six months, the average exercise volumes in the low-dose and highdose groups were $141.5 \pm 9.92 \mathrm{~min} /$ week $(92.8 \pm 2.44 \%$ of prescribed dose) and $247.2 \pm 10.71 \mathrm{~min} /$ week $(89.0 \pm 2.64 \%$ of prescribed dose), respectively. Daily caloric intake (group-by-time interaction $P=0.743$ ) and the proportion of daily calories from carbohydrate sources (group-bytime interaction $P=0.645$ ) were not significantly different from baseline to six months in any of the groups.

Metabolic growth factor concentrations are presented in Table 2. Fasting insulin concentration, the pre-specified key growth factor outcome, decreased $7.4 \pm 9.4 \mathrm{pmol} / \mathrm{L}$ in the control group, $28.0 \pm 8.3 \mathrm{pmol} / \mathrm{L}$ in the low-dose group and $20.7 \pm 9.3 \mathrm{pmol} / \mathrm{L}$ in the high-dose group (nonlinear $P_{\text {trend }}=0.042$; Fig. 1). Similarly, insulin resistance decreased $0.11 \pm 0.20$ in the control group, $0.63 \pm 0.17$ in the low-dose group and $0.43 \pm 0.19$ in the high-dose group (nonlinear $P_{\text {trend }}=0.012$ ). Fasting glucose concentration decreased in the low-dose group, whereas no difference was observed in high-dose and control groups (nonlinear $P_{\text {trend }}=0.004$ ). IGF-1, IGFBP-3, fructosamine and C-peptide did not change in any of the study groups. Adjustment for type 2 diabetes mellitus as a covariate in the regression models did not substantively alter the above-described findings. No serious (grade $\geq 3$ ) adverse events occurred. Nonserious (grade 1-2) adverse events occurred at similar rates among the three groups (Brown et al. 2017a).

Table 2 Metabolic growth factor outcomes at baseline and change during six months.

\begin{tabular}{|c|c|c|c|}
\hline Outcome & Baseline (mean \pm S.D.) & $\Delta$ Baseline to month 6 (LS mean \pm S.E.) & $\Delta$ from control (LS mean $(95 \% \mathrm{Cl}))$ \\
\hline \multicolumn{4}{|l|}{ Insulin, pmol/L } \\
\hline Control & $99.2 \pm 60.5$ & $-7.36 \pm 9.41$ & - \\
\hline Low-dose & $101.8 \pm 40.5$ & $-28.02 \pm 8.35^{a}$ & $-20.66(-45.32,3.99)$ \\
\hline High-dose & $135.1 \pm 87.1$ & $-20.70 \pm 9.35^{a}$ & $-13.34(-39.33,12.6)$ \\
\hline Test for trend & & Linear, $P=0.170 ;$ Nonlinear, $P=0.042$ & \\
\hline \multicolumn{4}{|l|}{ Glucose, $\mathrm{mmol} / \mathrm{L}$} \\
\hline Control & $5.3 \pm 1.0$ & $0.01 \pm 0.16$ & - \\
\hline Low-dose & $5.3 \pm 0.8$ & $-0.39 \pm 0.15^{a}$ & $-0.39(-0.83,0.05)$ \\
\hline High-dose & $6.1 \pm 2.3$ & $-0.09 \pm 0.17$ & $-0.09(-0.56,0.38)$ \\
\hline Test for trend & & Linear, $P=0.931 ;$ Nonlinear, $P=0.004$ & \\
\hline \multicolumn{4}{|l|}{ Insulin resistance (HOMA) } \\
\hline Control & $2.2 \pm 1.3$ & $-0.11 \pm 0.20$ & - \\
\hline Low-dose & $2.2 \pm 0.9$ & $-0.63 \pm 0.17 a$ & $-0.52(-1.03,-0.01)^{b}$ \\
\hline High-dose & $2.9 \pm 2.0$ & $-0.43 \pm 0.19 a$ & $-0.32(-0.86,0.22)$ \\
\hline Test for trend & & Linear, $P=0.125 ;$ Nonlinear, $P=0.012$ & \\
\hline \multicolumn{4}{|l|}{ IGF-1, $\mathrm{nmol} / \mathrm{L}$} \\
\hline Control & $58.0 \pm 15.9$ & $-4.57 \pm 3.23$ & - \\
\hline Low-dose & $59.8 \pm 13.2$ & $-0.94 \pm 3.21$ & $3.63(-5.29,12.56)$ \\
\hline High-dose & $64.7 \pm 17.5$ & $1.62 \pm 3.57$ & $6.19(-3.25,15.62)$ \\
\hline \multicolumn{4}{|l|}{ IGFBP-3, nmol/L } \\
\hline Control & $1765.1 \pm 446.8$ & $-103.71 \pm 69.15$ & - \\
\hline Low-dose & $1925.7 \pm 449.5$ & $-30.01 \pm 68.04$ & $73.69(-116.96,264.34)$ \\
\hline High-dose & $2290.0 \pm 748.2$ & $-154.28 \pm 71.97^{a}$ & $-50.58(-246.83,145.68)$ \\
\hline Test for trend & & Linear, $P=0.685 ;$ Nonlinear, $P=0.093$ & \\
\hline \multicolumn{4}{|l|}{ C-peptide, $\mathrm{nmol} / \mathrm{L}$} \\
\hline Control & $0.64 \pm 0.4$ & $0.007 \pm 0.033$ & - \\
\hline Low-dose & $0.58 \pm 0.3$ & $-0.003 \pm 0.032$ & $-0.010(-0.10,0.08)$ \\
\hline High-dose & $0.75 \pm 0.3$ & $-0.013 \pm 0.035$ & $-0.020(-0.11,0.07)$ \\
\hline Test for trend & & Linear, $P=0.701 ;$ Nonlinear, $P=0.934$ & \\
\hline \multicolumn{4}{|l|}{ Fructosamine, $\mathrm{mmol} / \mathrm{L}$} \\
\hline Control & $201.4 \pm 20.5$ & $2.60 \pm 16.82$ & - \\
\hline Low-dose & $183.0 \pm 51.2$ & $22.91 \pm 15.84$ & $20.31(-24.98,65.60)$ \\
\hline High-dose & $204.1 \pm 28.6$ & $-12.65 \pm 16.96$ & $-15.26(-62.08,31.57)$ \\
\hline Test for trend & & Linear, $P=0.380 ;$ Nonlinear, $P=0.382$ & \\
\hline
\end{tabular}

$\mathrm{Cl}$, confidence interval; HOMA, homeostatic model assessment; LS mean, least-squares mean; s.E., standard error; s.D., standard deviation. Changes in outcomes are estimated using a linear mixed-effects regression model that adjusted for the baseline value of the dependent variable and cancer stage (randomization stratification factor).

aSignifcantly different from baseline (within-group), $P \leq 0.05$; ${ }^{b}$ Significantly different from control, $P \leq 0.05$. 


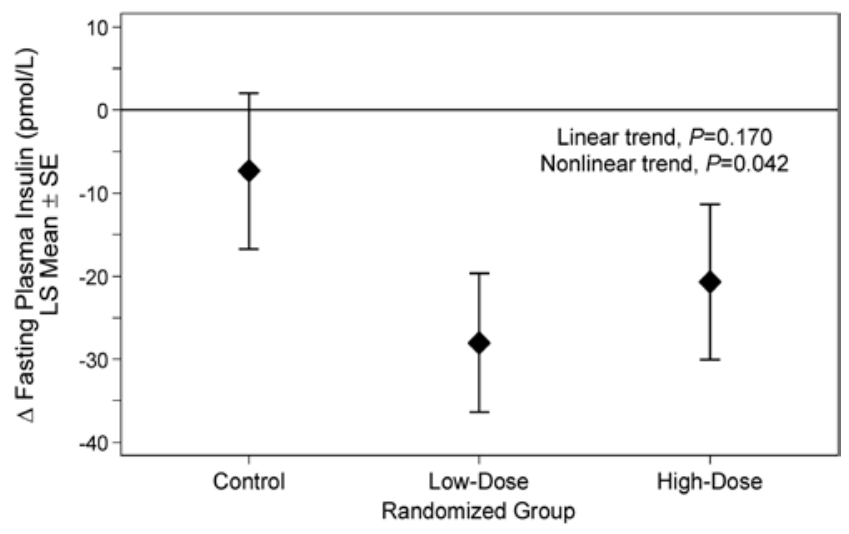

Figure 1

Between-group changes in fasting insulin concentration from baseline to six months.

We previously reported that exercise reduced visceral adipose tissue in a dose-response fashion (linear $P_{\text {trend }}=0.008$ ), such that each $60 \mathrm{~min} /$ week increase in exercise volume predicted a $-2.7 \pm 1.4 \mathrm{~cm}^{2}$ reduction in visceral adipose tissue (Brown et al. 2017b). For each $1 \mathrm{~cm}^{2}$ reduction in visceral adipose tissue, fasting insulin concentrations were lowered by $0.96 \pm 0.41 \mathrm{pmol} / \mathrm{L}$ $(P=0.025$; Table 3, Fig. 2); changes in visceral adipose tissue accounted for $13.5 \%$ of the shared variance of changes in fasting insulin concentrations. Changes in visceral adipose tissue were also correlated with changes in fasting glucose and insulin resistance. Adjustment for visceral adipose tissue did not alter the relationship between exercise dose and fasting insulin concentrations (nonlinear $P_{\text {trend }}=0.042$ ) or insulin resistance (nonlinear $\left.P_{\text {trend }}=0.010\right)$.

Table 3 Relationship between change in visceral adipose tissue (per $1 \mathrm{~cm}^{2}$ reduction) and change in metabolic growth factor concentration during six months.

\begin{tabular}{|c|c|c|c|}
\hline Outcome & $\begin{array}{c}\Delta \text { in metabolic } \\
\text { growth factor } \\
\text { concentration } \\
\text { (LS mean } \pm \text { S.E.) }\end{array}$ & $R^{2}$ & $\boldsymbol{P}$ \\
\hline Insulin, pmol/L & $-0.96 \pm 0.41$ & $13.5 \%$ & 0.025 \\
\hline Glucose, $\mathrm{mmol} / \mathrm{L}$ & $-0.03 \pm 0.01$ & $21.9 \%$ & 0.004 \\
\hline Insulin resistance (HOMA) & $-0.024 \pm 0.009$ & $16.5 \%$ & 0.013 \\
\hline IGF-1, nmol/L & $-0.22 \pm 0.13$ & $7.6 \%$ & 0.098 \\
\hline IGFBP-3, nmol/L & $-1.22 \pm 3.16$ & $0.4 \%$ & 0.701 \\
\hline C-peptide, $\mathrm{mmol} / \mathrm{L}$ & $0.0007 \pm 0.001$ & $0.6 \%$ & 0.650 \\
\hline Fructosamine, $\mathrm{mmol} / \mathrm{L}$ & $-0.16 \pm 0.47$ & $0.3 \%$ & 0.736 \\
\hline
\end{tabular}

LS mean, least-squares mean; $R^{2}$, proportion of variability of change in metabolic growth factor concentration explained by change in visceral adipose tissue; S.E., standard error.

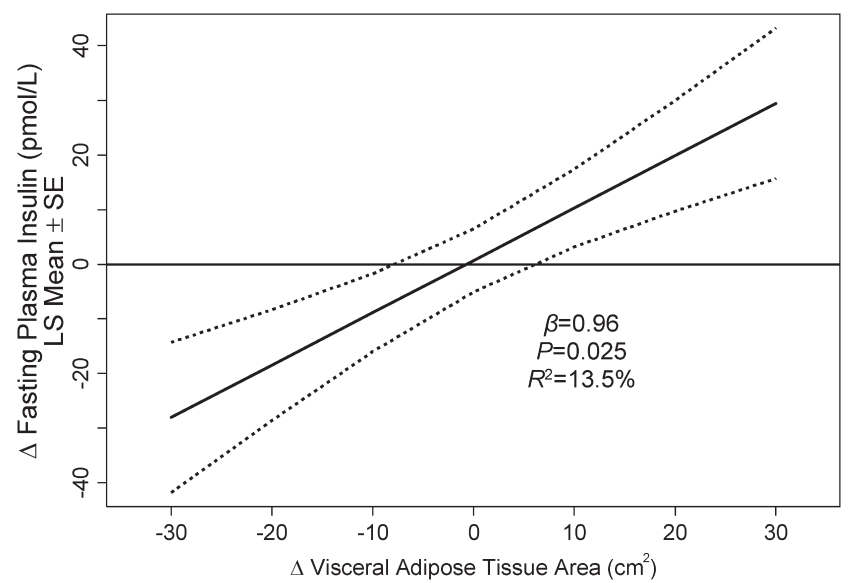

Figure 2

Relationship between changes in visceral adipose tissue area and changes in fasting insulin concentration from baseline to six months.

\section{Discussion}

A six-month moderate-intensity aerobic exercise program among stage I-III colon cancer survivors reduced fasting insulin concentrations and insulin resistance in a predominately overweight and obese population. The findings from this randomized trial support the hypothesis that the relationship between physical activity and colon cancer prognosis may be mediated, in part, by changes in fasting insulin concentrations or insulin resistance.

The reductions in fasting insulin concentrations and insulin resistance with exercise are similar to those observed in a prior dose-response study in overweight and obese adults (Ross et al. 2015). This prior study demonstrated that fasting insulin concentrations and insulin resistance may be lowered to a similar magnitude across distinct doses of exercise (Ross et al. 2015). However, the absolute magnitude of reduction in fasting insulin concentrations in our study was larger than that of others (Houmard et al. 2004, Ross et al. 2015). This may be the result of our sample having higher baseline fasting insulin concentrations $(111 \mathrm{pmol} / \mathrm{L}$ in the current study vs $49 \mathrm{pmol} / \mathrm{L}$ (Houmard et al. 2004) and $67.5 \mathrm{pmol} / \mathrm{L}$ (Ross et al. 2015)), which is consistent with the observation that colon cancer survivors have significantly higher fasting insulin concentrations than healthy persons (Jiang et al. 2014). Our findings are similar to studies in breast cancer survivors that exercise reduces fasting insulin concentrations (Ligibel et al. 2008, Irwin et al. 2009).

In prior cross-sectional analyses, fasting insulin concentrations were higher with larger areas of visceral adipose tissue, an effect that is attributable to increased insulin resistance (Goodpaster et al. 2003). 
We demonstrated that changes in visceral adipose tissue accounted for $13.5 \%$ of the shared variance in insulin concentration, which is similar to studies in obese men that estimated the shared variance to be $16-22 \%$ (Rice et al. 1999, Borel et al. 2017). These data suggest that the effects of exercise to lower fasting insulin may include mechanisms beyond that of changes in visceral adipose tissue. We hypothesize that alterations in skeletal muscle insulin resistance and free fatty acid (FFA) metabolism may help to further explain this effect (DeFronzo \& Tripathy 2009, Abdul-Ghani \& DeFronzo 2010). Insulin resistance in skeletal muscle is associated with hyperinsulinemia (DeFronzo \& Tripathy 2009, Abdul-Ghani \& DeFronzo 2010) and the inability to lower FFA in the postprandial state (Jensen 2008). Skeletal muscle preferentially oxidizes FFA (Randle et al. 1963), suppressing insulin-stimulated glucose uptake into the muscle (Boden et al. 1994, Dresner et al. 1999). Exercise improves the insulin suppression of FFA release (Shadid \& Jensen 2006), corrects the mismatch between FFA uptake and FFA oxidation (Turcotte \& Fisher 2008) and promotes insulin-stimulated glucose uptake into skeletal muscle (Hayashi et al. 1997).

The biologic or biobehavioral pathways through which exercise may alter cancer outcomes are unknown. States of hyperinsulinemia activate the PI3K-Akt-mTOR pathway (McCurdy \& Klemm 2013). In preclinical experiments, activation of the PI3K-Akt-mTOR pathway promotes the growth of colon cancer metastases (Gulhati et al. 2011), and inhibition of this pathway induces cellcycle arrest and apoptosis (Zhang et al. 2009). Insulin receptor substrate 1 (IRS1) is a mediator of glucose homeostasis, and the downregulation of IRS1 is associated with insulin resistance (Karlsson \& Zierath 2007). Colonic tumor expression of IRS1 and physical activity interact to influence colon cancer outcomes (Hanyuda et al. 2016). Among patients with the decreased expression of IRS1, physical activity is associated with a significantly lower risk of colon cancer-specific mortality $\left(P_{\text {trend }}=0.005\right)$, whereas no relationship is observed with IRS2. IRS1 is associated with insulin metabolism in skeletal muscle, whereas IRS2 is associated with insulin metabolism in the liver (Karlsson \& Zierath 2007). These observational data provide additional support to the hypothesis that exercise may have an insulin-sensitizing effect that is produced through skeletal muscle contractions, and this insulin sensitization may influence disease outcomes.

There are several limitations to this trial. The main limitation is the small sample size which limits the generalizability of our findings. We have previously reported that participants in this trial were younger than the population from which they were recruited (Brown et al. 2016). Because of the small sample size, we observed numeric differences at baseline in selected metabolic growth factor concentrations. Our plan of analyses pre-specified that the baseline value of the dependent variable would be included in the model to account for baseline differences; however, we cannot rule out that the observed differences may be partly due to regression to the mean. The small sample size precluded our ability to undertake formal mediation analysis to explore the relationships among exercise dose, visceral adipose tissue and insulin concentrations (Friedenreich et al. 2011). The small sample size also limited our statistical power to examine other metabolic growth factors such as IGF-1. Additional randomized studies with larger sample sizes are needed to confirm our findings. It is not known if the relationship between exercise dose and change in insulin concentrations is linear at the population level. If a linear relationship does exist, there may be a several reasons why we did not identify such a relationship. Our study was only six months in duration. It is unknown if the observed improvements in outcomes would be sustained or improved upon over a longer time horizon. Participants were not recruited based on having hyperinsulinemia; however, $82 \%$ of our study sample was overweight or obese; consequently, hyperinsulinemia was common. We examined two distinct volumes of moderate-intensity aerobic exercise, but we did not examine the effects of light- or vigorous intensity aerobic exercise (McGarrah et al. 2016) or resistance exercise (either as a single modality or prescribed in combination with aerobic exercise).

There are several strengths to this trial. The use of two intervention groups, each prescribed a distinct dose of exercise, allowed us to examine changes in fasting insulin along the exercise dose curve. The exercise program, which emphasized home-based treadmill walking, promoted good intervention adherence that was confirmed with objective heart rate monitor measures. Most participants (97\%) completed the study.

In summary, the findings from this phase II randomized dose-response trial demonstrate that moderate-intensity aerobic exercise reduces fasting insulin concentrations and insulin resistance among patients with stage I-III colon cancer. The findings from this randomized trial may be useful to help guide exercise prescriptions in this population. The relationship between physical activity and colon cancer prognosis may be mediated, in part, by changes in insulin concentrations or insulin resistance. Continued research to examine this hypothesis is warranted. 


\section{Declaration of interest}

The authors declare that there is no conflict of interest that could be perceived as prejudicing the impartiality of the research reported.

\section{Funding}

This research was supported by R21-CA182767, F31-CA192560 and U54CA155850 from the National Cancer Institute, P30-DK019525 from the National Institute of Diabetes and Digestive and Kidney Diseases and UL1-TR000003 from the National Center for Research Resources and the National Center for Advancing Translation Science. This research was supported by discounts for treadmills from LifeSpan Fitness, LLC (Salt Lake City, UT). The content is solely the responsibility of the authors and does not necessarily represent the official views of the National Institutes of Health.

\section{Author contribution statement}

All authors were involved in the study design. J C B, A B T, B K and $\mathrm{K}$ H S collected and analyzed the data in conjunction with the authors. The manuscript was written by J C B, and was reviewed, modified and approved in its final version by all the authors. All authors vouch for the accuracy and completeness of the data reported and the fidelity of the study to the protocol.

\section{Acknowledgements}

The authors thank the Pennsylvania Cancer Registry for their role in recruitment activities for this study. The authors also thank Dr. Heather Collins of the University of Pennsylvania Diabetes Research Center for conducting the assays used to quantify metabolic growth factor outcomes.

\section{References}

Abdul-Ghani MA \& DeFronzo RA 2010 Pathogenesis of insulin resistance in skeletal muscle. Journal of Biomedicine and Biotechnology 2010 476279. (https://doi.org/10.1155/2010/476279)

Ainsworth BE, Haskell WL, Whitt MC, Irwin ML, Swartz AM, Strath SJ, O'Brien WL, Bassett DR Jr, Schmitz KH, Emplaincourt PO, et al. 2000 Compendium of physical activities: an update of activity codes and MET intensities. Medicine and Science in Sports and Exercise 32 S498-S504. (https://doi.org/10.1097/00005768-200009001-00009)

Belfiore A \& Malaguarnera R 2011 Insulin receptor and cancer. EndocrineRelated Cancer 18 R125-R147. (https://doi.org/10.1530/ERC-11-0074)

Boden G, Chen X, Ruiz J, White JV \& Rossetti L 1994 Mechanisms of fatty acid-induced inhibition of glucose uptake. Journal of Clinical Investigation 93 2438-2446. (https://doi.org/10.1172/JCI117252)

Borel AL, Nazare JA, Baillot A, Almeras N, Tremblay A, Bergeron J, Poirier P \& Despres JP 2017 Cardiometabolic risk improvement in response to a 3-yr lifestyle modification program in men: contribution of improved cardiorespiratory fitness vs weight loss. American Journal of Physiology: Endocrinology and Metabolism $\mathbf{3 1 2}$ E273-E281. (https://doi.org/10.1152/ajpendo.00278.2016)

Brown JC, Troxel AB, Ky B, Damjanov N, Zemel BS, Rickels MR, Rhim AD, Rustgi AK, Courneya KS \& Schmitz KH 2016 A randomized phase II dose-response exercise trial among colon cancer survivors: purpose, study design, methods, and recruitment results. Contemporary Clinical Trials 47 366-375. (https://doi. org/10.1016/j.cct.2016.03.001)

Brown JC, Troxel AB, Ky B, Damjanov N, Zemel BS, Rickels MR, Rhim AD, Rustgi AK, Courneya KS \& Schmitz KH $2017 a$
Dose-response effects of aerobic exercise among colon cancer survivors: a randomized phase II trial. Clinical Colorectal Cancer [epub]. (https://doi.org/10.1016/j.clcc.2017.06.001)

Brown JC, Zemel BS, Troxel AB, Rickels MR, Damjanov N, Ky B, Rhim AD, Rustgi AK, Courneya KS \& Schmitz KH 2017b Doseresponse effects of aerobic exercise on body composition among colon cancer survivors: a randomized controlled trial. British Journal of Cancer [epub]. (https://doi.org/10.1038/bjc.2017.339)

Chen J, Huang XF, Qiao L \& Katsifis A 2011a Insulin caused drug resistance to oxaliplatin in colon cancer cell line HT29. Journal of Gastrointestinal Oncology 2 27-33. (https://doi.org/10.3978/j. issn.2078-6891.2010.028)

Chen J, Katsifis A, Hu C \& Huang XF $2011 b$ Insulin decreases therapeutic efficacy in colon cancer cell line HT29 via the activation of the PI3K/Akt pathway. Current Drug Discovery Technologies 8 119-125. (https://doi.org/10.2174/157016311795563820)

DeFronzo RA \& Tripathy D 2009 Skeletal muscle insulin resistance is the primary defect in type 2 diabetes. Diabetes Care 32 S157-S163. (https://doi.org/10.2337/dc09-S302)

Dresner A, Laurent D, Marcucci M, Griffin ME, Dufour S, Cline GW, Slezak LA, Andersen DK, Hundal RS, Rothman DL, et al. 1999 Effects of free fatty acids on glucose transport and IRS-1-associated phosphatidylinositol 3-kinase activity. Journal of Clinical Investigation 103 253-259. (https://doi.org/10.1172/JCI5001)

Fernandez MC, Rayes R, Ham B, Wang N, Bourdeau F, Milette S, Lllemann M, Bird N, Majeed A, Xu J, et al. 2016 The type I insulinlike growth factor regulates the liver stromal response to metastatic colon carcinoma cells. Oncotarget 8 52281-52293. (https://doi. org/10.18632/oncotarget.12595)

Fitzmaurice GM, Laird NM \& Ware JH 2012 Applied Longitudinal Analysis. Hoboken, NJ, USA: John Wiley \& Sons.

Friedenreich CM, Neilson HK, Woolcott CG, McTiernan A, Wang Q, Ballard-Barbash R, Jones CA, Stanczyk FZ, Brant RF, Yasui Y, et al. 2011 Changes in insulin resistance indicators, IGFs, and adipokines in a yearlong trial of aerobic exercise in postmenopausal women. EndocrineRelated Cancer 18 357-369. (https://doi.org/10.1530/ERC-10-0303)

Fu T, Pappou EP, Guzzetta AA, Calmon Mde F, Sun L, Herrera A, Li F, Wolfgang CL, Baylin SB, Iacobuzio-Donahue CA, et al. 2016 IGFBP-3 gene methylation in primary tumor predicts recurrence of stage II colorectal cancers. Annals of Surgery 263 337-344. (https://doi org/10.1097/SLA.0000000000001204)

Goodpaster BH, Krishnaswami S, Resnick H, Kelley DE, Haggerty C, Harris TB, Schwartz AV, Kritchevsky S \& Newman AB 2003 Association between regional adipose tissue distribution and both type 2 diabetes and impaired glucose tolerance in elderly men and women. Diabetes Care 26 372-379. (https://doi.org/10.2337/ diacare.26.2.372)

Gulhati P, Bowen KA, Liu J, Stevens PD, Rychahou PG, Chen M, Lee EY, Weiss HL, O'Connor KL, Gao T, et al. 2011 mTORC1 and mTORC2 regulate EMT, motility, and metastasis of colorectal cancer via RhoA and Rac1 signaling pathways. Cancer Research 71 3246-3256. (https://doi.org/10.1158/0008-5472.CAN-10-4058)

Hanyuda A, Kim SA, Martinez-Fernandez A, Qian ZR, Yamauchi M, Nishihara R, Morikawa T, Liao X, Inamura K, Mima K, et al. 2016 Survival benefit of exercise differs by tumor IRS1 expression status in colorectal cancer. Annals of Surgical Oncology 23 908-917. (https://doi.org/10.1245/s10434-015-4967-4)

Hayashi T, Wojtaszewski JF \& Goodyear LJ 1997 Exercise regulation of glucose transport in skeletal muscle. American Journal of Physiology 273 E1039-E1051.

Haydon AM, Macinnis RJ, English DR, Morris H \& Giles GG 2006 Physical activity, insulin-like growth factor 1, insulin-like growth factor binding protein 3, and survival from colorectal cancer. Gut $\mathbf{5 5}$ 689-694. (https://doi.org/10.1136/gut.2005.081547)

Houmard JA, Tanner CJ, Slentz CA, Duscha BD, McCartney JS \& Kraus WE 2004 Effect of the volume and intensity of exercise 
training on insulin sensitivity. Journal of Applied Physiology 96 101-106. (https://doi.org/10.1152/japplphysiol.00707.2003)

Irwin ML, Varma K, Alvarez-Reeves M, Cadmus L, Wiley A, Chung GG, Dipietro L, Mayne ST \& Yu H 2009 Randomized controlled trial of aerobic exercise on insulin and insulin-like growth factors in breast cancer survivors: the Yale Exercise and Survivorship study. Cancer Epidemiology, Biomarkers and Prevention 18 306-313. (https://doi. org/10.1158/1055-9965.EPI-08-0531)

Je Y, Jeon JY, Giovannucci EL \& Meyerhardt JA 2013 Association between physical activity and mortality in colorectal cancer: a meta-analysis of prospective cohort studies. International Journal of Cancer 133 1905-1913. (https://doi.org/10.1002/ijc.28208)

Jensen MD 2008 Role of body fat distribution and the metabolic complications of obesity. Journal of Clinical Endocrinology and Metabolism 93 S57-S63. (https://doi.org/10.1210/jc.2008-1585)

Jiang B, Zhang X, Du LL, Wang Y, Liu DB, Han CZ, Jing JX, Zhao XW \& Xu XQ 2014 Possible roles of insulin, IGF-1 and IGFBPs in initiation and progression of colorectal cancer. World Journal of Gastroenterology 20 1608-1613. (https://doi.org/10.3748/wjg.v20.i6.1608)

Karlsson HK \& Zierath JR 2007 Insulin signaling and glucose transport in insulin resistant human skeletal muscle. Cell Biochemistry and Biophysics 48 103-113. (https://doi.org/10.1007/s12013-007-0030-9)

Koenuma M, Yamori T \& Tsuruo T 1989 Insulin and insulin-like growth factor 1 stimulate proliferation of metastatic variants of colon carcinoma 26. Japanese Journal of Cancer Research 80 51-58. (https://doi.org/10.1111/j.1349-7006.1989.tb02244.x)

Lee DH, Kim JY, Lee MK, Lee C, Min JH, Jeong DH, Lee JW, Chu SH, Meyerhardt JA, Ligibel J, et al. 2013 Effects of a 12-week home-based exercise program on the level of physical activity, insulin, and cytokines in colorectal cancer survivors: a pilot study. Support Care Cancer 21 2537-2545. (https://doi.org/10.1007/s00520-013-1822-7)

Levy JC, Matthews DR \& Hermans MP 1998 Correct homeostasis model assessment (HOMA) evaluation uses the computer program. Diabetes Care 21 2191-2192. (https://doi.org/10.2337/diacare.21.12.2191)

Ligibel JA, Campbell N, Partridge A, Chen WY, Salinardi T, Chen H, Adloff K, Keshaviah A \& Winer EP 2008 Impact of a mixed strength and endurance exercise intervention on insulin levels in breast cancer survivors. Journal of Clinical Oncology 26 907-912. (https://doi.org/10.1200/JCO.2007.12.7357)

McCurdy CE \& Klemm DJ 2013 Adipose tissue insulin sensitivity and macrophage recruitment: does PI3K pick the pathway? Adipocyte $\mathbf{2}$ 135-142. (https://doi.org/10.4161/adip.24645)

McGarrah RW, Slentz CA \& Kraus WE 2016 The effect of vigorousversus moderate-intensity aerobic exercise on insulin action. Current Cardiology Reports 18 117. (https://doi.org/10.1007/s11886016-0797-7)

Paffenbarger R, Wing A \& Hyde R 1978 Paffenbarger physical activity questionnaire. American Journal of Epidemiology 108 161-175. (https://doi.org/10.1093/oxfordjournals.aje.a112608)

Randle PJ, Garland PB, Hales CN \& Newsholme EA 1963 The glucose fatty-acid cycle. Its role in insulin sensitivity and the metabolic disturbances of diabetes mellitus. Lancet 1 785-789. (https://doi. org/10.1016/S0140-6736(63)91500-9)

Rice B, Janssen I, Hudson R \& Ross R 1999 Effects of aerobic or resistance exercise and/or diet on glucose tolerance and plasma insulin levels in obese men. Diabetes Care 22 684-691. (https://doi. org/10.2337/diacare.22.5.684)
Ross R, Hudson R, Stotz PJ \& Lam M 2015 Effects of exercise amount and intensity on abdominal obesity and glucose tolerance in obese adults. A randomized trial effects of exercise on obesity and glucose intolerance. Annals of Internal Medicine 162 325-334. (https://doi. org/10.7326/M14-1189)

Schmid D \& Leitzmann M 2014 Association between physical activity and mortality among breast cancer and colorectal cancer survivors: a systematic review and meta-analysis. Annals of Oncology 25 1293-1311. (https://doi.org/10.1093/annonc/mdu012)

Schousboe JT, Langsetmo L, Schwartz AV, Taylor BC, Vo TN, Kats AM, Barrett-Connor E, Orwoll ES, Marshall LM, Miljkovic I, et al. 2017 Comparison of associations of DXA and CT visceral adipose tissue measures with insulin resistance, lipid levels, and inflammatory markers. Journal of Clinical Densitometry 20 256-264. (https://doi. org/10.1016/j.jocd.2017.01.004)

Shadid S \& Jensen MD 2006 Pioglitazone increases non-esterified fatty acid clearance in upper body obesity. Diabetologia 49 149-157. (https://doi.org/10.1007/s00125-005-0051-0)

Siegel R, Desantis C \& Jemal A 2014 Colorectal cancer statistics, 2014. CA: A Cancer Journal for Clinicians 64 104-117. (https://doi. $\operatorname{org} / 10.3322 /$ caac. 21220)

Siegel RL, Miller KD \& Jemal A 2016 Cancer statistics, 2016. CA: A Cancer Journal for Clinicians 66 7-30. (https://doi.org/10.3322/ caac.21332)

Simons CC, Schouten LJ, Godschalk RW, van Engeland M, van den Brandt PA, van Schooten FJ \& Weijenberg MP 2015 Genetic variants in the insulin-like growth factor pathway and colorectal cancer risk in the Netherlands cohort study. Scientific Reports 514126 (https://doi.org/10.1038/srep14126)

Tran TT, Medline A \& Bruce WR 1996 Insulin promotion of colon tumors in rats. Cancer Epidemiology, Biomarkers and Prevention 5 1013-1015.

Troiano RP, Berrigan D, Dodd KW, Masse LC, Tilert T \& McDowell M 2008 Physical activity in the United States measured by accelerometer. Medicine and Science in Sports and Exercise 40 181-188. (https://doi.org/10.1249/mss.0b013e31815a51b3)

Turcotte LP \& Fisher JS 2008 Skeletal muscle insulin resistance: roles of fatty acid metabolism and exercise. Physical Therapy 88 1279-1296. (https://doi.org/10.2522/ptj.20080018)

Volkova E, Robinson BA, Willis J, Currie MJ \& Dachs GU 2014 Marginal effects of glucose, insulin and insulin-like growth factor on chemotherapy response in endothelial and colorectal cancer cells. Oncology Letters 7 311-320. (https://doi.org/10.3892/ol.2013.1710)

Wargny M, Balkau B, Lange C, Charles M-A, Giral P \& Simon D 2017 Association of fasting serum insulin and cancer mortality in a healthy population-28-year follow-up of the French TELECOM Study. Diabetes and Metabolism [epub]. (https://doi.org/10.1016/j. diabet.2017.03.006)

Wolpin BM, Meyerhardt JA, Chan AT, Ng K, Chan JA, Wu K, Pollak MN, Giovannucci EL \& Fuchs CS 2009 Insulin, the insulin-like growth factor axis, and mortality in patients with nonmetastatic colorectal cancer. Journal of Clinical Oncology 27 176-185. (https://doi. org/10.1200/JCO.2008.17.9945)

Zhang Y-J, Dai Q, Sun D-F, Xiong H, Tian X-Q, Gao F-H, Xu M-H, Chen G-Q, Han Z-G \& Fang J-Y 2009 mTOR signaling pathway is a target for the treatment of colorectal cancer. Annals of Surgical Oncology 16 2617-2628. (https://doi.org/10.1245/s10434-009-0555-9)

Received in final form 20 September 2017

Accepted 10 October 2017

Accepted preprint published online 10 October 2017 